\title{
Admission serum glucose level as a marker of outcome severe head injury patients
}

\author{
Raghavendra Nayak ${ }^{1}$, Bhagwati Salgotra ${ }^{2, *}$, Dhruv N. Patel ${ }^{3}$, Marci Juneja ${ }^{4}$, Deval Patel ${ }^{5}$ \\ ${ }^{1,2}$ Associate Professor, ${ }^{3} 3^{\text {rd }}$ year Student,,${ }^{4,5} 1^{\text {st }}$ year Student, ${ }^{3}$ Dept. of Neurosurgery, ${ }^{4}$ Dept. of General Surgery, ${ }^{1}$ Kasturba \\ Medical College, Manipal, Karnataka, ${ }^{2-5}$ Sumandeep Vidyapeeth Dhiraj Hospital, Vadodara, Gujarat, India
}

*Corresponding Author:

Email: drsalgotra@gmail.com

\begin{abstract}
Introduction: Hyperglycemia is a one of the common response to stress especially when it is related to the tissue injury like head injury. The purpose of this study was to detect the effect of admission hyperglycemia on the overall mortality and morbidity in the patients of severe head injury.

Materials and Methods: Retrospective methods were used in this study and this study includes patients with severe TBI. The patients were divided into two groups: Hyperglycemia group and normal blood sugar level group. This was based on the serum glucose level. The Outcome measures of the study were mortality and Glasgow Outcome Scale which were recorded at 6 months. Results: A total of 160 patients (male $=112$, female $=48$ ) were included in this study who had severe TBI and also met the inclusion criteria. The mean $( \pm \mathrm{SD})$ age of the patients taken for this study was $46.5( \pm 11.5)$ years. The mean GCS of the patients at the time of admission was $5.2 \pm 1.5$. The mean $( \pm \mathrm{SD})$ serum glucose level within 24 hours of admission was $249 \mathrm{mg} / \mathrm{dL}$ with lowest being $110 \mathrm{mg} / \mathrm{dL}$ and highest of $390 \mathrm{mg} / \mathrm{dL}$. Fifty-five (34\%) patients had hyperglycemia (glucose level $>200 \mathrm{mg} / \mathrm{dL}$ ) at admission and remaining 105 patients $(66 \%)$ had normal serum magnesium levels. Hyperglycemia resulted in $55 \%$ of the total mortality ( $\mathrm{N}=30)$ compared to $38 \%(\mathrm{~N}=40)$ in patients who had normal blood glucose level after 24 hours of admission. The mortality rate is significantly higher in patients with hyperglycemia $(\chi 2=3.68 ; \mathrm{P}=0.04)$. The assessment of the patients with Glasgow outcome score was done at 6 months follow up. 80\% (N=44) of the patients who had high blood sugar levels showed the poor Glasgow outcome compared to the patients with normal blood glucose where 66\% ( $\mathrm{N}=65)$ which was statistically significant $(\chi 2=5.44 ; \mathrm{p}=.019)$

Conclusion: Hyperglycemia at admission increases the rate of mortality and morbidity in head injury patients.
\end{abstract}

Keywords: Hyperglycemia, Severe head injury, Glasgow outcome scale.

\section{Introduction}

Traumatic brain injury (TBI) is one of the leading cause resulting in mortality and morbidity. It has a major impact on socioeconomic status because the majority consists of the young patients. Not just the initial impact but also there are several other biochemical mechanisms which gets activated in severe TBI patients, determine the outcome, and thus the imbalances among these mechanisms ultimately lead to secondary injuries. ${ }^{1}$

Hyperglycemia is a common phenomenon in acute stress like injury. Better management of hyperglycemia in acute disorder is associated with the better clinical outcome. ${ }^{2,3}$

But the least importance is given to the glycemic control in head injury. ${ }^{4,5}$ So, the purpose of this study was to assess the effect of high blood sugar levels on the overall outcome of patients who had severe head injury.

\section{Materials and Methods}

The type of study was prospective which includes the patients admitted over a period from 2015 to 2018 at a tertiary care center to assess the effect of high blood sugar levels on the out-come of the patients with severe head injury. The study includes the adult traumatic brain injury patients with GCS $\leq 8$ and admission within 24 hrs. of injury. Patients who had multiple organ injuries, low blood pressure (systolic $<90$ ), history suggestive of diagnosed diabetes mellitus in a patient, $\mathrm{HbA} 1 \mathrm{c}$ levels more than 7.5 and presence of any type of chronic systemic illness were excluded from the study. The data pertaining to GCS score, age, gender and serum glucose levels within the $24 \mathrm{hrs}$ of the admission was collected. Patients were then divided into two groups depending on the initial serum glucose level: patients with glucose level $<200 \mathrm{mg} / \mathrm{dL}$ group and patients with hyperglycemia group (Glucose level $>200 \mathrm{mg} / \mathrm{dL}$ ). Patients with hyperglycemia were adequately treated with the injection Insulin.

Standard care included the ventilator support, seizure prophylaxis, antibiotic prophylaxis, prophylaxis for gastric ulcer, and catheterization for urine. When computerized tomography (CT) imaging of the brain reflected a focal mass effect or a diffuse cerebral edema, only then injection Mannitol was included in the treatment. The decision for surgical decompression was taken after assessing the CT brain findings and it was different for each patient. 


\section{Results}

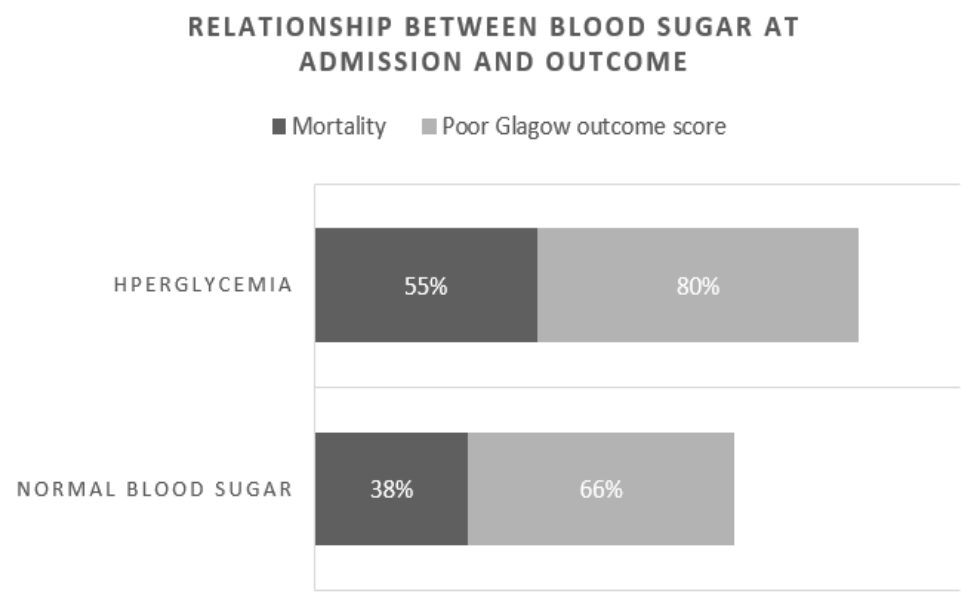

\section{Fig. 1: Showing the relationship between blood sugar at admission and outcome}

A total of 160 patients $($ male $=112$, female $=48)$ with severe head injury who covered all the inclusion criteria were taken for the study. The mean $( \pm \mathrm{SD})$ age of the patients chosen for this study was $46.5( \pm 11.5)$ years. The mean Glasgow coma scale of the patients chosen for this study at the time of admission was $5.2 \pm$ 1.5. The mean $( \pm \mathrm{SD})$ serum glucose level within 24 hours of admiss ion was $249 \mathrm{mg} / \mathrm{dL}$ with lowest being $110 \mathrm{mg} / \mathrm{dL}$ and highest of $390 \mathrm{mg} / \mathrm{dL}$. Fifty-five (34\%) patients had hyperglycemia (glucose level $>200 \mathrm{mg} / \mathrm{dL}$ ) at the time of admission and the remaining 66\% (105 patients) of population shows serum glucose levels within normal limit. Hyperglycemia resulted in high mortality rate which was $55 \%(\mathrm{~N}=30)$ compared to $38 \%(\mathrm{~N}=40)$ in those patients who had normal blood glucose level 24 hours after the admission. The mortality rate is significantly higher in patients having high blood sugar levels. $(\chi 2=3.68 ; \mathrm{P}=0.04)$. The assessment of the patients with Glasgow outcome score was done after an interval of 6 months when patients came for follow up. The Glasgow outcome score was poor among $80 \% \quad(\mathrm{~N}=44)$ of patients who had hyperglycemia compared to the patients with normal blood glucose where $66 \% \quad(\mathrm{~N}=65)$ which was statistically significant $(\chi 2=5.44 ; \quad p=.019)$. No significant difference was found with respect to age and initial Glasgow coma scale.

\section{Discussion}

Hyperglycemia is a one of the common response to stress especially when it is related to the tissue injury like head injury. And stress hyperglycemia is related to increased chances of death, congestive cardiac failure and cardiogenic shock. ${ }^{6}$

Catecholamines levels start increasing as a result of Hyperglycemia due to stress. Once the release of steroids starts increasing, it further leads to increase release of glucagon and inhibition of insulin release which in turn increases the serum sugar levels. ${ }^{7}$

Persistent hyperglycemia causes electrolyte imbalances, decreases the immunity and creates a noxious environment by forming free radicles. Even modest amount of hyperglycemia in the ICU is related to the significant increase in the mortality. ${ }^{8}$

Once the blood sugar levels are controlled by aggressive use of insulin administration it further leads to good clinical outcome and reduction in the mortality by $42 \%$ as shown by one randomized control trial. ${ }^{9}$

Hyperglycemia at the time of admission is thus an independent factor predicting the further outcome and the infection rate in patients of trauma as proven by Sung et al. ${ }^{10}$

Study done by Yendamari et al including 738 trauma patients shows that significantly increases both intensive care unit stay and overall hospital stay. And there was increase in both mortality and morbidity in these patients. ${ }^{11}$

Mechanism by which hyperglycemia influences the head injury outcome is still uncertain. Hyperglycemia is usually mediated by the stress induced multiple neuronal and hormonal changes. ${ }^{12}$ Even level of serum cortisol is associated with the mortality in head injury. ${ }^{13}$ Certain studies shows that serum insulin is correlated well with the degree of coma after head injury. ${ }^{14}$

In our study, it is shown that high blood sugar levels i.e. Hyperglycemia at the time of admission results in increase of mortality as well as morbidity following head injury. Further larger studies are required to confirm this finding.

\section{Conclusion}

Hyperglycemia at admission results in higher incidence of mortality as well as morbidity in head injury patients. 


\section{References}

1. Reilly PL. Brain injury: The pathophysiology of the first hours. 'Talk and die revisited'. J Clin Neurosci 2001;8:398- 403.

2. Golden SH, Peart-Vigilance C, Kao WH, Brancati FL. Perioperative glycemic control and the risk of infectious complicationsin a cohort of adults with diabetes. Diabetes Care 1999;22(9):1408-14.

3. Kjersem H, Hilsted J, Madsbad S, Wandall JH, Johansen KS, Borregaard N. Polymorphonuclear leucocyte dysfunctionduring short term metabolic changes from normo- to hyperglycemia in type 1 (insulin dependent) diabetic patients. Infection 1988;16(4):215-221.

4. Marion DW, Spiegel TP. Changes in the management of severe traumatic brain injury: 1991-1997. Crit Care Med 2000;28:16-18.

5. Murray GD, Teasdale GM, Braakman R, et al. The European brain injury consortium survey of head injuries. Acta Neurochir (Wien). 1999;141:223-36.

6. 6.Capes SE, Hunt D, Malmberg K, Gerstein HC. Stress hyperglycaemia and increased risk of death after myocardialinfarction in patients with and without diabetes: a systematic overview. Lancet 2000;355(9206):773-78.

7. Mizock BA. Alterations in carbohydrate metabolism duringstress: a review of the literature. Am J Med 1995;98(1):75-84.

8. Krinsley JS. Association between hyperglycemia and increased hospital mortality in a heterogeneous population of critically ill patients. Mayo Clin Proc 2003;78(12):1471-78.

9. Young B, Ott L, Dempsey R, Haack D, Tibbs P. Relationship between admission hyperglycemia and neurologic outcome of severely brain-injured patients. Ann Surg 1989; 210:466-73.

10. Sung J, Bochicchio GV, Joshi M, Bochicchio K, Tracy K, Scalea TM. Admission hyperglycemia is predictive of outcome in critically ill trauma patients. J Trauma 2005;59(1):80-3.

11. Yendamari S, Fulda J, Tinkoff G. Admission hyperglycemia as a prognostic indicator in trauma. $J$ Trauma 2003;55:33-8.

12. Woolf PD, Hamill RW, Lee LA, Cox C, McDonald JV. The predictive value of catecholamines in assessing outcome in traumatic braininjury. J Neurosurg 1987;66:875-82.

13. Van den Berghe G, Wouters P, Weekers F, Verwaest C, Bouillon R. Intensive insulin therapy in critically ill patients. N Engl J Med 2001;345:1359-67.

14. Bosarge PL, Shoultz TH, Griffin RL, et al. Stress-induced hyperglycemia is associated with higher mortality in severe traumatic brain injury. J Trauma Acute Care Surg 2015;79(2):289-94. 